\title{
Nanomedicine in chemoradiation
}

\author{
Seth M Miller and Andrew Z Wang* \\ Department of Radiation Oncology \& Laboratory of Nano- \& Translational, Medicine, University of \\ North, Carolina, Chapel Hil, NC, USA
}

\section{Abstract}

Chemoradiotherapy, the concurrent administration of chemotherapy and radiotherapy, is a treatment paradigm in oncology. It is part of the standard of care and curative treatment of many cancers. Given its importance, one of the primary goals of cancer research has been to identify agents and/or strategies that can improve the therapeutic index of chemoradiation. Recent advances in nanomedicine have provided a unique and unprecedented opportunity for improving chemoradiotherapy. Nanoparticles possess properties that are ideally suited for delivering chemotherapy in the chemoradiation setting. The goal of this review is to examine the role of incorporating nanomedicine into chemoradiation and the potential impact of nanomedicine to chemoradiotherapy.

Cancer is the leading cause of death worldwide and the second leading cause of death in the USA [1]. The curative treatment of cancer generally involves multiple specialties including surgery, chemotherapy and radiation therapy. Surgery and radiation therapy are both local treatments. The goal of surgery is to remove the primary tumor, while radiation is used to treat any residual disease and macrometastases that are known to surround the primary tumor. Chemotherapy works systemically to eradicate micrometastatic disease. In recent years, clinical research has established that combining the above treatment modalities is the standard of care and has improved survival and cure in many cancers such as those of the breasts and lungs $[2,3]$.

Part of the multimodality treatment of cancer is the chemoradiotherapy treatment paradigm. Chemoradiotherapy, the concurrent administration of chemotherapy and radiotherapy, is part of the standard of care in the curative management of many cancers. Its origin traces back to the 1970s when Nigro and colleagues demonstrated that combining mitomycin C, 5fluorouracil, and radiation for anal cancer could lead to complete resolution of disease [4]. This landmark paper lead to further use of combined chemotherapy and radiation therapy in the neo-adjuvant, definitive and adjuvant settings [5]. In chemoradiation, chemotherapy acts as a radio-sensitizer to enhance local control and, potentially, overall survival while also eradicating distant micrometastatic disease [5].

\footnotetext{
(C) 2013 Future Science Ltd

*Author for correspondence: Tel.: +1 919966 0400, Fax: +1 919966 0805, andrew_wang@med.unc.edu.

For reprint orders, please contact reprints@ future-science.com
}

Financial \& competing interests disclosure

AZ Wang has a consulting agreement with Samyang Biopharmaceuticals Corporation. He is also supported by a National Institutes of Health/National Cancer Institute K12 Career Development Award 5-K12-CA120780-01-05 and National Institutes of Health Center for Nanotechnology Excellence Grant 1-U54-CA151652-01. The authors have no other relevant affiliations or financial involvement with any organization or entity with a financial interest in or financial conflict with the subject matter or materials discussed in the manuscript apart from those disclosed.

No writing assistance was utilized in the production of this manuscript. 
In the last two decades, the use of chemoradiation has expanded widely to brain, head and neck, esophageal, lung (small cell and non-small cell), pancreatic, gastric, sarcoma, bladder, cervical, vulvar, rectal and anal cancers [2,5-14]. It has been shown to improve local tumor control, overall survival and cure. This includes superior outcomes when compared with the sole use of chemotherapy, radiation therapy, or even sequential delivery of both $[2,5,8]$. For inoperable patients, concurrent chemoradiation provides a treatment option with curative intent, as is the case in many patients with lung cancer [2].

Another benefit of concurrent chemoradiation is potential organ-sparing approaches to treatment [5]. The goal of organ preservation is to not only cure the patient's cancer, but also spare critical structures, avoid disfiguring surgery and maintain high quality-of-life after treatment. Head and neck, anal, rectal, and bladder cancers are often treated with surgical resection that permanently alters patient function [9-13]. Larynx preservation with definitive chemoradiation can preserve a patient's voice while avoiding a laryngectomy [9].

Chemoradiation for anal and rectal cancer may allow a patient to avoid an abdominoperineal resection, which involves a permanent colostomy bag $[4,11,12]$. Radical cystectomy is the gold standard for treating invasive bladder cancer. A recent publication adds to the growing body of literature showing that concurrent chemoradiation may be an excellent bladdersparing approach to treatment [13].

While chemoradiation appears to be an outstanding option in many disease sites, there are increased levels of toxicity associated with concurrent therapy $[9,14]$. They may lead to prolonged treatment courses, reduction in dose of chemotherapy or radiation therapy, or an incomplete course of treatment, all of which may lead to worse disease outcomes. Some physicians may not offer concurrent chemoradiation due to concern over a patient's inability to tolerate the rigors of treatment, thus, putting them at a decreased chance of cure prior to starting treatment. Even for those who finish treatment, complete resolution of tumor may only be seen in a small fraction of patients [15]. Hence, there is room for improvement, especially if higher efficacy and similar or lower toxicities can be achieved.

Numerous other approaches have been pursued to increase the therapeutic ratio without much success. Intra-arterial chemotherapy in head and neck cancer has been explored to improve drug delivery to the site of disease. However, in a Phase III trial it showed no advantage in locoregional control or survival, while increasing neurologic toxicity [16]. Others have attempted to use nitroimidazole compounds (i.e., misonidazole, nimorazole and etanidazole) as radiosensitizers $[17,18]$. They mimic oxygen and work by making hypoxic tumor cells more sensitive to treatment. Unfortunately, insufficient drug delivery to the tumor and associated toxicity has limited their utility to date [17,19]. One approach for targeted therapy involves biologic agents such as cetuximab and bevacizumab [15,20]. These drugs act by blocking specific cell molecules, such as EGFR or VEGF, with a goal of interfering with tumor or microenvironment growth. While some applications of targeted therapies have shown promise, as is the case with cetuximab in head and neck cancer [20], other examples show only a modest improvement, such as bevacizumab in rectal cancer [15]. Furthermore, toxicity remains a problem. There have been reports of dermatologic manifestations and, in some regions of the USA, life-threatening anaphylaxis [21,22]. While there are multiple approaches being investigated, an optimal solution remains elusive.

Ideally, the best agent for chemoradiation would go directly to the tumor and remain there while not accumulating in adjacent normal tissues. Conventional chemotherapy is a systemic but nonspecific therapy that cannot achieve this goal. However, newer technologies in nanomedicine and the application of nanotechnology to medicine, may provide solutions to this targeting problem. Nanoparticles (NPs), by definition, are typically less than $100 \mathrm{~nm}$ in size, biodegradable, biocompatible and possess unique properties that permit targeted 
approaches to delivering various chemotherapeutics. This revolution in technology is potentially a major breakthrough when applied to chemoradiation.

In this review, the authors will provide background information on nanomedicine, provide examples of the benefit of intersecting it with chemoradiation, discuss the current NP platforms, including those already evaluated for chemoradiation, and assess the advantages and disadvantages of NP therapies in chemoradiation. The goal of this review is to examine the role of incorporating nanomedicine into chemoradiation and its potential impact on cancer treatment.

\section{NP advantages in chemoradiation}

\section{The enhanced permeability \& retention effect}

Tumor angiogenesis differs from normal vascular biology in many ways, providing therapeutic opportunities for NPs. While normal tissue vascular biology exhibits a highly organized structure, tumor vasculature is disorganized and irregularly branched [23-28]. Furthermore, there is a heterogeneous density of vessels in the tumor and the defective architecture includes a more porous endothelium, with vascular pores ranging from less than $100-2000 \mathrm{~nm}$ in size, compared with normal pores of 5-10 nm [24,28,29]. Lymphatic vessels, which are normally responsible for removing excess fluid from tissue, often function only at the tumor periphery, which leads to inefficient fluid drainage, providing another opportunity for NP accumulation at the tumor [23,25]. This combination of features - irregular tumor vasculature structure, high vascular density within the tumor, increased tumor vessel permeability and defective lymphatic drainage - has been named the enhanced permeability and retention (EPR) factor $[25,27]$. This feature allows NPs to accumulate in high concentration within the tumor, while minimal accumulation occurs in adjacent and systemic normal tissue.

\section{Preferential accumulation in tumor}

As Jain et al. describe, any therapeutic agent traveling from the systemic circulation to the tumor requires three steps. First, it flows via blood vessels to different regions of the tumor. It then crosses the blood vessel wall and finally penetrates the interstitial space at the target cells [23].

Based on this process, NP size leads to a preferential accumulation in tumors compared with small-molecule therapeutics. The EPR effect typically creates a favorable tumor to normal tissue dose gradient, which may lead to greater treatment efficacy while sparing more healthy tissue. This is an advantage compared with traditional chemotherapy where nonspecific systemic distribution may lead to toxicity in the heart, lung, kidneys or nerves and, in turn, limit tolerance to a full course of therapy.

NP clearance is another important advantage. While chemotherapy may be processed via multiple routes for excretion from the body, NPs are mainly removed from the circulation via the mononuclear phagocytic system (MPS) and hepatic excretion [30]. MPS (formerly known as the reticuloendothelial system) processing may lead to excretion in bile or accumulation of NPs within the Kupffer cells of the liver and macrophages in the spleen [30,31]. The distinctive properties of NP accumulation and clearance enhance the therapeutic ratio by reducing the amount of systemic toxicity experienced compared with small-molecule therapeutics [32].

Chemoradiation uses radiosensitizing doses of chemotherapy, given concurrently with fulldose radiation therapy, to create a synergistic response to both treatments. However, this approach uses small molecules that will diffuse into both normal and malignant tissue, 
increasing the risk of normal tissue toxicity. In this setting, NP preferential tumor accumulation should minimize the side effect profile in combined modality treatment. Metabolism is critically important as we apply NPs to chemoradiation. For example, radiation treatment fields that are at or near the liver will need to be developed carefully because of an increased risk of hepatic toxicity. There are already dose constraints to organs at risk when performing treatment planning for radiation therapy, but these may need to be adjusted when using concurrent NP-based therapeutics. While this is an important consideration, NPs have the potential to not only enhance the ability to tolerate and complete treatment, but they may also permit systemic therapy dose escalation or radiation therapy dose de-escalation due to their specific, beneficial properties.

\section{NP therapeutics under preclinical \& clinical evaluation}

As mentioned earlier, NPs are generally defined as particles that are less than or equal to 100 $\mathrm{nm}$. They are designed to carry systemic therapies while also being biodegradable and biocompatible. With this definition in mind, decades of research has led to the development of five categories: liposomes, albumin-bound, polymeric, dendrimers and metal NPs.

\section{Liposomes}

There are numerous liposomal formulations currently approved for clinical use in the USA, with more in the drug-development pipeline. They are spherical, layered vesicles that selfassemble when placed in water [33]. They range in size from $50 \mathrm{~nm}$ to micrometers, which permits loading with a variety of therapeutics, including simultaneous small molecules and macromolecules [33-36]. Liposomes are classically eliminated by the MPS system; however, PEG can be added to the liposome surface and significantly enhance circulation half-life, which allows for increased tumor accumulation [37]. There are already multiple clinical approvals for liposomal-based NP chemotherapeutics (Table 1). DaunoXome ${ }^{\circledR}$ (liposomal daunorubicin) is used to treat AIDS-related Kaposi's sarcoma, acute myeloid leukemia and non-Hodgkin's Lymphoma [38-41]. PEGylated liposomal doxorubicin, also called Doxil $^{\circledR}$ or Caelyx ${ }^{\circledR}$, is approved to treat AIDS-related Kaposi's sarcoma, multiple myeloma, and ovarian and breast cancers [23,42-45]. Non-PEGylated liposomal doxorubicin $\left(\right.$ Myocet $\left.^{\circledR}\right)$ is used in Europe as first-line treatment for breast cancer, where trials have shown similar outcomes, but less cardiac and hematopoietic toxicity $[41,46]$. The large size variation and easy construction will permit for a growing list of clinical applications, particularly in oncology, of liposomal NPs.

\section{Albumin-bound NPs}

The NP albumin-bound (nab) platform uses albumin to shuttle hydrophobic therapeutics. Albumin is an ubiquitous serum protein that naturally carries molecules in the bloodstream, attached by reversible noncovalent binding [47]. Albumin enters cells via glycoprotein 60 receptor-mediated transcyctosis, permitting excellent transport of nab drugs [48]. This clear molecular pathway has translated to clinical success: Abraxane ${ }^{\circledR}$, a combination of a 130-nm nab with the chemotherapeutic drug paclitaxel, has shown a $25 \%$ increase in overall response while demonstrating an improved safety profile when compared with paclitaxel alone in metastatic breast cancer [49,50]. Follow-up studies have validated the increased efficacy and safety profile, even in a geriatric patient cohort (i.e., 265 -years-old) [51]. This has led to studies evaluating Abraxane in lung, esophageal and ovarian cancers, as well as melanoma [52]. While the only US FDA-approved indication is for metastatic breast cancer, there are more than 1500 ongoing clinical trials involving Abraxane, which should lead to expansion of the approval for treatment of additional disease sites [201]. It is important to note that nab-paclitaxel does not possess all classic NP properties, as its 130-nm particles dissociate into 10-nm complexes once they are diluted in plasma [53]. Further understanding 
of the mechanism of action and pharmacokinetics of nab-based therapeutics will lead to better targeting and development of new drugs on this platform [54-57].

\section{Polymeric NPs}

Polymeric NPs are one of the areas of greatest research interest. They form biocompatible and biodegradable particles in an aqueous environment $[58,59]$. They exhibit great versatility with a high-loading capacity that can include hydrophilic or hydrophobic small molecules, as well as macromolecules such as proteins and nucleic acids [60]. An additional advantage of polymeric NPs is the potential for biological targeting and subsequent improved drug delivery. Aptamers, antibodies and folate molecules can be engineered into NPs $[58,61-70]$. While functionalizing NPs with targeting ligands is not unique to polymeric NPs, they are distinctive in their ability to be tailored prior to particle assembly. Modulating docetaxel release by altering NP construction is just one clinical example of these features. Using the particle replication in non-wetting templates process, precise control of NP size and shape can be consistently reproduced, providing a model for development and design of other NPs [71].

In the preclinical setting, a group in Asia showed higher therapeutic efficacy in vivo with taxane-containing polymeric NPs (paclitaxel and docetaxel) treating non-small cell lung cancer (NSCLC) [72]. Genexol-PM, a polymeric micelle formulation of paclitaxel, is clinically approved to treat breast and lung cancer in South Korea, while ongoing trials are evaluating its use in NSCLC, metastatic breast, pancreatic and advanced urothelial cancers [73-78]. Preclinical data exists on BIND-014, a targeted NP docetaxel NP, showing prolonged circulation, controlled release, enhanced tumor accumulation and prolonged tumor growth suppression when compared with conventional docetaxel [79]. This promising data has led to a Phase I clinical trial that is now accruing patients with metastatic cancer [202]. Finally, Phase I data of docetaxel-PNP on 19 patients with solid tumors was recently presented, establishing a maximum tolerated dose of $60 \mathrm{mg} / \mathrm{m}^{2}$, leading the way for Phase II studies of this polymeric NP chemotherapeutic agent [80].

\section{Dendrimers}

Dendrimers are composed of macromolecules, such as amino acids, nucleotides and sugars. They form well-defined and regularly branched structures which afford great flexibility in design and modification for use as NPs. They are readily modified, with drugs linked via chemical bonds or inserted into the dendrimer core via hydrophobic interactions. There are no den-drimer NPs currently approved for clinical use, but preclinical research continues to focus on dendrimer-drug conjugate development [81].

\section{Metal NPs}

Gold, titanium and other metals have been used to modify chemotherapy release, primarily constructed as a nanoshell to control drug release [82]. Despite being inert and biocompatible, a high proportion of the particles are not excreted, creating a toxicity profile that has limited advancement past preclinical studies [30]. Gadolinium, a heavy metal used in MRI imaging, may afford opportunities to serve as a diagnostic and therapeutic NP. Early animal model studies show promise for this approach as a radiosensitizer and imaging contrast agent [83]. Nonetheless, there are no clinically approved metal NPs to date.

\section{NP therapeutics used in chemoradiation}

While there are many NP therapeutics in clinical and preclinical development for the treatment of cancer, those approved for use in humans include only doxorubicin, daunorubicin, nab-paclitaxel and polymeric NP paclitaxel. With only a few clinically 
available NPs, even less data exist for concurrent chemoradiation. This creates a new field of research as more NPs come to market.

\section{Liposome trials}

Liposomal-based anthracyclines were the first NP therapeutics approved for human use. Current commercially available products include PEGylated liposomal doxorubicin (trade name Caelyx abroad and Doxil in the USA), liposomal daunorubicin (DaunoXome), and nonP-EGylated liposomal doxorubicin (Myocet) [84]. Clinically, DaunoXome is approved to treat Kaposi's sarcoma and has promising Phase III clinical trial data in non-Hodgkin's lymphoma and acute myeloid leukemia $[39,40,47]$.

Concurrent Caelyx and radiation therapy has been pursued in multiple small clinical trials. As reported by Koukourakis and colleagues in 1999, 30 patients (15 with NSCLC and 15 with squamous cell carcinoma of the head and neck) safely received definitive treatment, with tolerable toxicity profiles including the expected mucositis [85]. They demonstrated preferential accumulation of technetium-tagged Caelyx in tumor on SPECT scans, which correlated with treatment response. While not the primary endpoint of the trial, there were complete response rates of $21 \%$ in NSCLC and $75 \%$ in head and neck cancer, which are encouraging numbers for two difficult-to-treat disease sites [85]. This was followed by a study from the same group where 25 patients with stage IIIB NSCLC were treated with Caelyx, docetaxel and conventionally fractionated radiotherapy [86]. Patients were also dosed with amifostine, a radioprotector, with a goal of reducing side effects from treatment. While $36 \%$ of the patients experienced grade 3 esophagitis, the regimen was otherwise well tolerated, which is encouraging in a disease where 5-year survival rates are approximately $15 \%$. Phase I data in 2004 examined the combination of concurrent Caelyx, cisplatin, and radiotherapy for head and neck and lung squamous cell carcinoma [87]. A total of 18 patients were entered on the trial and the limiting toxicity was grade 3 mucositis, including treatment breaks of at least 7 days for three of the patients. These are important complications, but well within the expected rates with conventional treatment approaches. In another multimodality combination, Caelyx, oxaliplatin, amifostine and hypofractionated concurrent radiotherapy were combined to treat 29 stage IIIb and two stage IV patients with NSCLC [88]. Grade 3 esophagitis was the main toxicity, modest complete and partial response rates (39 and 55\%, respectively) were seen, and 2-year follow-up data showed progression-free survival of 58\% and overall survival of $45 \%$ [88]. Building upon this data, Koukourakis et al. exchanged vinorelbine for oxaliplatin to treat 14 patients with stage IIIb or IV NSCLC [89]. Esophagitis occurred at expected rates, but this study revealed increased grade 3 neutropenia, leading to treatment delays in approximately $30 \%$ of the patients.

While there are some small trials exploring liposomal doxorubicin with concurrent radiation therapy in lung cancer, fewer still exist for other disease sites. Varveris and colleagues, the same group publishing many of the lung cancer studies, pursued a Phase I/II study with Caelyx in cervical cancer. They used concurrent cisplatin and radiation, establishing an maximum tolerated dose of $12 \mathrm{mg} / \mathrm{m}^{2} /$ week and showing that nearly $30 \%$ of the patients (seven of 24) had a complete response to this treatment regimen [90]. In two breast cancer trials, patients received liposomal doxorubicin (PEGylated and non-PEGylated), docetaxel, and radiation therapy; patients with her-2/neu overexpressing tumors also received the molecularly targeted therapy trastuzumab [91,92]. Both studies established the feasibility of treating breast cancer with concurrent chemoradiotherapy. In bladder cancer, 38 patients received definitive treatment with amifostine and radiation therapy, with or without liposomal doxorubicin [93]. With nearly 2 years of follow-up, there was a $10 \%$ increase in complete response rate with the addition of Caelyx, while no difference in toxicity was noted. 
This group of studies shows early promising results with concurrent Caelyx/Doxil and radiation therapy. However, further advances towards large Phase II and randomized Phase III clinical trials have not yet been shown. This may be due to the well-described cardiotoxicity profile of anthracyclines. Without long-term data, further clinical application of anthracycline-based NPs may be hampered, especially in thoracic malignancies such as lung and breast cancer where the heart may be directly exposed to both therapies.

Liposomal cisplatin has been studied in a few early clinical trials, including one where 12 patients received Lipoplatin ${ }^{\mathrm{TM}}, 5$-fluorouracil and concurrent radiation therapy for locally advanced gastric cancer [94]. Patients experienced toxicities consistent with conventional cisplatin, while actually reporting improved performance status 2 months after completion of treatment. Increasing the number of cycles of combined chemotherapy improved the complete response rate from 33 to $80 \%$, although the number of total patients in each group (six and five, respectively) was small. Regardless, these are very encouraging early results that merit further investigation.

In head and neck cancer, concurrent chemo-radiation with weekly cisplatin is often employed with curative intent, but can be a difficult treatment course due to multiple acute toxicities. Rosenthal et al., evaluated dose escalation with liposomal cisplatin and concurrent radiation therapy. After infusion reactions were addressed by slowing rates and further diluting Lipoplatin, treatment-related toxicity was similar to that of concurrent cisplatin [95]. As is the case with Caelyx/Doxil, Lipoplatin has sparse but encouraging early-phase clinical data and is yet to be tested in larger clinical trials.

\section{Albumin-bound NP data}

Abraxane, an albumin-bound 130-nm NP-containing paclitaxel, has already been approved for the treatment of breast cancer and is actively being investigated in other tumor types [96]. There are preclinical data on its role as a radio-sensitizer in breast and ovarian cancer. Interesting timing data came out of this study- the best responses were seen when radiation was initiated 2-3 days after administration of nab-paclitaxel, without apparent increases in normal tissue toxicity [57]. Outside of this paper, a search of the literature yields few publications involving concurrent administration of abraxane and radiation therapy. However, this will seemingly change in the coming years, as evidenced by a subsequent search [203], where "abraxane AND concurrent AND radiation" yields 99 results, with 33 active clinical trials [204]. This includes a number of Phase III clinical trials in lung, esophageal, head and neck, endometrial and cervical cancer using a combination of multiple agents, including chemotherapy and molecularly targeted therapies, increasing the need to have a tolerable toxicity profile that may be afforded by NP-based chemotherapeutics.

\section{Polymeric NP data}

The authors' group has evaluated a combined lipid-polymeric docetaxel NP as a radiosensitizer in a preclinical model of head and neck cancer. While there is data that conventional docetaxel is an excellent radiosensitizer, it requires a solvent to be administered, which can be the source of numerous toxicities. Encapsulation in a lipidpolymer NP may eliminate this issue [97,98]. Further targeting of this NP can be achieved by adding folate to the surface [61]. This may be particularly useful in head and neck cancer where folate is often an overexpressed surface marker [99].

After validating folate-mediated uptake of NPs in an in vitro head and neck cell line, preclinical studies in a xenograft head and neck cancer mouse model were pursued. Folatetargeted NPs lead to increased radiosensitization over both conventional docetaxel and nonfolate-targeted NP docetaxel [61]. As was seen in preclinical studies with nab-paclitaxel, 
there again appears to be optimal timing for delivery of folate-targeted docetaxel NPs, but the underlying mechanism has not been discovered. These data provide an encouraging approach to use not only NPs, but also molecular surface receptors to further target treatment delivery [61].

A combination of polymeric NP features is seen in the targeted NP docetaxel NP BIND-014, which is now entering Phase I clinical trials $[79,100]$. Nonetheless, Genexol-PM, remains the only clinically approved polymeric NP chemotherapy to date [73]. It is approved for the treatment of breast and lung cancer in Asia. While research into its role in advanced NSCLC, metastatic breast cancer, pancreatic cancer and advanced urothelial cancer is ongoing, it has not been evaluated for use in concurrent chemoradiation [74-78].

\section{NPs \& biologic therapies}

The combination of NPs and biologic therapies in chemoradiation has also been pursued. Some biologic agents cannot be administered systemically, so NPs may be a way to safely and effectively deliver these treatments. Examples to date include delivery of gene therapy, such as antisense oligonucleotides and siRNA, as well as radioprotective agents.

Davis etal. reported development of CALAA-01, a polymeric NP containing siRNA targeting the M2 subunit of RRM2 in solid tumors [101]. Initial clinical data showed high levels of NP accumulation in melanoma biopsies, which correlated with downregulation of RRM2 messenger RNA and protein levels. This has led to a Phase I clinical trial assessing safety, toxicity and the specific pharmacokinetics of this siRNA-based NP [205]. Another study looked at inhibiting the DNA repair gene $A T M$, to magnify chemoradiation response [102]. Preclinical data in mice, using a polymeric nanoparticle that contains antisense $A T M$ oligonucleotides, showed ATM protein expression reduction prior to radiation therapy..

The therapeutic ratio can be altered by attempting to sensitize tumor tissue to treatment, as is the case above, or by enhancing normal tissue tolerance. The latter approach was pursued using a liposomal NP containing manganese superoxide dismutase, a protein that diminishes ionizing radiation damage [103]. Plasmid-based liposomal manganese superoxide dismutase was given during a Phase I trial of concurrent paclitaxel, carboplatin and radiation therapy in patients with stage III NSCLC. Ten patients were enrolled, no dose-limiting toxicities were detected and a $70 \%$ overall response rate was achieved for the standard chemoradiation regimen [103]. This is particularly important because of the difficulty many stage III NSCLC patients have completing their treatment course as prescribed.

\section{Metal NP data}

Metal NPs have properties that naturally lead researchers to explore their use in radiosensitization. Gold NPs magnify radiation effects via electron scattering and preferential accumulation in tumor at high rates (i.e., 8:1 in one preclinical study) [104106]. A preclinical breast cancer study in mice showed that combined modality therapy using gold NPs followed by radiotherapy had an $86 \%$ 1-year survival rate, compared with $20 \%$ survival when treated with radiation therapy alone or $0 \%$ when using gold NPs alone. Furthermore, tumor response correlated with the amount of gold NPs received [106]. While renal clearance is the primary means of excretion, gold NP clinical applications remain limited due to the high dose needed and the overall poor post-treatment clearance of a potentially toxic heavy metal.

A Phase I clinical trial in France is evaluating NBTXR3, a metal NP containing hafnium oxide, for treatment of soft tissue sarcoma [206]. Somewhat unique to this study, the drug will be directly injected into the tumor. The NP is activated via electrons emitted after administration of high energy photons from external beam radiation therapy. Surgery will 
follow, which should provide interesting pathologic and pharmacokinetic information. Preclinical, in vitro data have shown this NP to be relatively inert and nontoxic, raising the hope for an effective clinical application of metal NPs [107].

Other groups have sought to develop a metal NP that can serve as both an imaging agent and a radiosensitizer, such as polysiloxane-coated gadolinium oxide NPs [83]. These particles can be detected by MRI up to 45 min post-injection. They, too, are renally excreted. Preclinical data in a rat gliosarcoma tumor model showed a median survival increase of 3 months when radiation therapy was delivered 20 min after NP administration [83].

\section{Revitalizing abandoned therapies}

There are therapeutics that were previously abandoned due to unfavorable systemic toxicity profiles. However, incorporating these drugs into NPs may reduce toxicity and reinvigorate their clinical applicability [108]. One recent example is a paper by the authors' group looking at Wortmannin (Wtmn), a furanosteroid metabolite of the fungi Penicillium funiculosum and Talaromyces (Penicillium) wortmannii. A lipid-polymer NP was engineered to include Wtmn and showed higher solubility while also demonstrating lower toxicity, as compared with conventional Wtmn. NP Wtmn also had promising in vitro results as a radiosensitizer, when compared with cisplatin. This led to in vivo studies, where Wtmn or NP Wtmn showed little effect on tumor growth. However, NP Wtmn followed by radiation therapy showed statistically significant tumor growth delay, with an apparent synergy between NP Wtmn and radiation therapy even compared with Wtmn and radiation therapy [108]. If other seemingly abandoned drugs can be revitalized by incorporating them into a NP platform, drug development could experience a paradigm shift in the approach to developing new anticancer therapies.

\section{Conclusion \& future perspective}

The authors have presented the wide array of NPs and their progress in development from theory through clinically approved and implemented NP chemotherapeutics. These particles have unique properties that make them well-suited for use in the treatment of cancer and especially in chemoradiotherapy. To date, nanomedicine, especially in oncology, has been focused on systemic therapies. However, identifying novel applications that take full advantage of the NP's properties will enhance the likely clinical success of these drugs. In this case, there is a clear need for advancing the paradigm of concurrent chemoradiation that merits further investigation at all levels (i.e., basic, translational, preclinical and clinical) of research. Early data allude to myriad opportunities for investigation, from the various combined modality approaches, to the timing of drug versus radiation therapy delivery $[30,68]$. Unfortunately, progress past a handful of small Phase I and II clinical trials has not been realized so far.

As new NP formulations are developed, rapid elucidation of drug characteristics will be important in accelerating the time from development to clinical application. The NP-based chemotherapeutics developed show promise in increasing the therapeutic ratio. However, the need continues to be great, and moving drugs past the preclinical stage and into the treatment paradigm of human cancers is critical. Further advancing that mission via concurrent chemoradiation must be one of the next steps. Understanding optimal combined modality approaches will be important as the protocols that pursue NP chemotherapeutic and radiation therapy dose escalation, or even de-escalation, depending on the need are established. As more sophisticated molecular targets are added to NPs, an even greater enhancement of the therapeutic ratio may be realized [79]. NP-based therapeutics are positioned to play a significant role in the improvement of treating cancer patients, especially with concurrent chemoradiation. The authors' goal is to achieve not only greater 
cure, but also lower toxicities, thus, providing patients with long and productive lives after treatment.

\title{
Key Terms
}

\author{
Chemoradiation \\ Combined use of chemotherapy and radiation therapy, typically \\ referring to their concurrent administration, for the treatment of \\ cancer
}

Therapeutic ratio

Also termed the therapeutic index, is a ratio of the therapeutic effect amount of toxicity

\section{References}

Papers of special note have been highlighted as:

- of interest

II of considerable interest

1. Siegel R, Ward E, Brawley O, Jemal A. Cancer statistics, 2011: the impact of eliminating socioeconomic and racial disparities on premature cancer deaths. CA Cancer J Clin. 2011; 61(4): 212-236. [PubMed: 21685461]

2. Curran WJ Jr, Paulus R, Langer CJ, et al. Sequential vs. concurrent chemoradiation for stage III non-small cell lung cancer: randomized Phase III trial RTOG 9410. J Natl Cancer Inst. 2011; 103(19):1452-1460. [PubMed: 21903745]

3. Overgaard M, Hansen PS, Overgaard J, et al. Postoperative radiotherapy in high-risk premenopausal women with breast cancer who receive adjuvant chemotherapy. Danish breast cancer cooperative group 82b Trial. N Engl J Med. 1997; 337(14):949-955. [PubMed: 9395428]

4. Nigro ND, Vaitkevicius VK, Considine B Jr. Combined therapy for cancer of the anal canal: a preliminary report. Dis Colon Rectum. 1974; 17(3):354-356. [PubMed: 4830803]

5. Seiwert TY, Salama JK, Vokes EE. The concurrent chemoradiation paradigm - general principles. Nat Clin Pract Oncol. 2007; 4(2):86-100. [PubMed: 17259930]

6. Stupp R, Mason WP, Van Den Bent MJ, et al. Radiotherapy plus concomitant and adjuvant temozolomide for glioblastoma. N Engl J Med. 2005; 352(10):987-996. [PubMed: 15758009]

7. Willett CG, Czito BG. Chemoradiotherapy in gastrointestinal malignancies. Clin Oncol (R Coll Radiol ). 2009; 21(7):543-556. [PubMed: 19577442]

8. Eifel PJ. Chemoradiotherapy in the treatment of cervical cancer. Semin Radiat Oncol. 2006; 16(3): 177-185. [PubMed: 16814159]

9. Forastiere AA, Goepfert H, Maor M, et al. Concurrent chemotherapy and radiotherapy for organ preservation in advanced laryngeal cancer. N Engl J Med. 2003; 349(22):2091-2098. [PubMed: 14645636]

10. Ajani JA, Winter KA, Gunderson LL, et al. Fluorouracil, mitomycin, and radiotherapy vs fluorouracil, cisplatin, and radiotherapy for carcinoma of the anal canal: a randomized controlled trial. JAMA. 2008; 299(16):1914-1921. [PubMed: 18430910]

11. Habr-Gama A, Perez RO, Nadalin W, et al. Operative versus nonoperative treatment for stage 0 distal rectal cancer following chemoradiation therapy: long-term results. Ann Surg. 2004; 240(4): 711-718. [PubMed: 15383798]

12. Maas M, Beets-Tan RG, Lambregts DM, et al. Wait-and-see policy for clinical complete responders after chemoradiation for rectal cancer. J Clin Oncol. 2011; 29(35):4633-4640. [PubMed: 22067400]

13. James ND, Hussain SA, Hall E, et al. Radiotherapy with or without chemotherapy in muscleinvasive bladder cancer. N Engl J Med. 2012; 366(16):1477-1488. [PubMed: 22512481] 
14. Cooper JS, Pajak TF, Forastiere AA, et al. Postoperative concurrent radiotherapy and chemotherapy for high-risk squamous-cell carcinoma of the head and neck. N Engl J Med. 2004; 350(19):1937-1944. [PubMed: 15128893]

15. Willett CG, Duda DG, Ancukiewicz M, et al. A safety and survival analysis of neoadjuvant bevacizumab with standard chemoradiation in a Phase I/II study compared with standard chemoradiation in locally advanced rectal cancer. Oncologist. 2010; 15(8):845-851. [PubMed: 20667969]

16. Wapnir IL, Dignam JJ, Fisher B, et al. Long-term outcomes of invasive ipsilateral breast tumor recurrences after lumpectomy in NSABP B-17 and B-24 randomized clinical trials for DCIS. J Natl Cancer Inst. 2011; 103(6):478-488. [PubMed: 21398619]

17. Grigsby PW, Winter K, Wasserman TH, et al. Irradiation with or without misonidazole for patients with stages IIIB and IVA carcinoma of the cervix: final results of RTOG 80-05. Radiation therapy oncology group. Int J Radiat Oncol Biol Phys. 1999; 44(3):513-517. [PubMed: 10348279]

18. Harrison LB, Chadha M, Hill RJ, Hu K, Shasha D. Impact of tumor hypoxia and anemia on radiation therapy outcomes. Oncologist. 2002; 7(6):492-508. [PubMed: 12490737]

19. Overgaard J, Bentzen SM, Kolstad P, et al. Misonidazole combined with radiotherapy in the treatment of carcinoma of the uterine cervix. Int J Radiat Oncol Biol Phys. 1989; 16(4):10691072. [PubMed: 2649463]

20. Bonner JA, Harari PM, Giralt J, et al. Radiotherapy plus cetuximab for squamous-cell carcinoma of the head and neck. N Engl J Med. 2006; 354(6):567-578. [PubMed: 16467544]

21. O'Neil BH, Allen R, Spigel DR, et al. High incidence of cetuximab-related infusion reactions in Tennessee and North Carolina and the association with atopic history. JClin Oncol. 2007; 25(24): 3644-3648. [PubMed: 17704414]

22. Chung $\mathrm{CH}$, Mirakhur B, Chan E, et al. Cetuximab-induced anaphylaxis and IgE specific for galactose-alpha-1,3-galactose. N Engl J Med. 2008; 358(11):1109-1117. [PubMed: 18337601]

23". Jain RK, Stylianopoulos T. Delivering nanomedicine to solid tumors. Nat Rev Clin Oncol. 2010; 7(11):653-664. Excellent review on nanomedicine advances, challenges and future directions in solid tumor biology. [PubMed: 20838415]

24. Noguchi Y, Wu J, Duncan R, et al. Early phase tumor accumulation of macromolecules: a great difference in clearance rate between tumor and normal tissues. Jpn J Cancer Res. 1998; 89(3):307314. [PubMed: 9600125]

25. Maeda H, Wu J, Sawa T, Matsumura Y, Hori K. Tumor vascular permeability and the EPR effect in macromolecular therapeutics: a review. J Control Release. 2000; 65(1-2):271-284. [PubMed: 10699287]

26. Chauhan VP, Stylianopoulos T, Martin JD, et al. Normalization of tumour blood vessels improves the delivery of nanomedicines in a size-dependent manner. Nat Nanotechnol. 2012; 7(6):383-388. [PubMed: 22484912]

27. Chauhan VP, Stylianopoulos T, Boucher Y, Jain RK. Delivery of molecular and nanoscale medicine to tumors: transport barriers and strategies. Annu Rev Chem Biomol Eng. 2011; 2:281298. [PubMed: 22432620]

28. Wilson WR, Hay MP. Targeting hypoxia in cancer therapy. Nat Rev Cancer. 2011; 11(6):393-410. [PubMed: 21606941]

29. Hobbs SK, Monsky WL, Yuan F, et al. Regulation of transport pathways in tumor vessels: role of tumor type and microenvironment. Proc Natl Acad Sci USA. 1998; 95(8):4607-4612. [PubMed: 9539785]

30. Longmire M, Choyke PL, Kobayashi H. Clearance properties of nano-sized particles and molecules as imaging agents: considerations and caveats. Nanomedicine (Lond). 2008; 3(5):703717. [PubMed: 18817471]

31. Almeida JP, Chen AL, Foster A, Drezek R. In vivo biodistribution of nanoparticles. Nanomedicine (Lond). 2011; 6(5):815-835. [PubMed: 21793674]

32. O'brien ME, Wigler N, Inbar M, et al. Reduced cardiotoxicity and comparable efficacy in a Phase III trial of pegylated liposomal doxorubicin $\mathrm{HCl}$ (CAELYX/Doxil) versus conventional doxorubicin for first-line treatment of metastatic breast cancer. Ann Oncol. 2004; 15(3):440-449. 
Study provided Phase III data on the use of nanomedicine-based chemotherapeutics. [PubMed: 14998846]

33. Ashley CE, Carnes EC, Phillips GK, et al. The targeted delivery of multicomponent cargos to cancer cells by nanoporous particle-supported lipid bilayers. Nat Mater. 2011; 10(5):389-397. [PubMed: 21499315]

34. Li SD, Chono S, Huang L. Efficient oncogene silencing and metastasis inhibition via systemic delivery of siRNA. Mol Ther. 2008; 16(5):942-946. [PubMed: 18388916]

35. Lammers T, Hennink WE, Storm G. Tumour-targeted nanomedicines: principles and practice. Br J Cancer. 2008; 99(3):392-397. [PubMed: 18648371]

36. de Davies CL, Lundstrom LM, Frengen J, et al. Radiation improves the distribution and uptake of liposomal doxorubicin (caelyx) in human osteosarcoma xenografts. Cancer Res. 2004; 64(2):547553. [PubMed: 14744768]

37. Zamboni WC. Concept and clinical evaluation of carrier-mediated anticancer agents. Oncologist. 2008; 13(3):248-260. [PubMed: 18378535]

38. Camera A, Rinaldi CR, Palmieri S, et al. Sequential continuous infusion of fludarabine and cytarabine associated with liposomal daunorubicin (DaunoXome) (FLAD) in primary refractory or relapsed adult acute myeloid leukemia patients. Ann Hematol. 2009; 88(2):151-158. [PubMed: 18709502]

39. Latagliata R, Breccia M, Fazi P, et al. Liposomal daunorubicin versus standard daunorubicin: long term follow-up of the GIMEMA GSI 103 AMLE randomized trial in patients older than 60 years with acute myelogenous leukaemia. Br J Haematol. 2008; 143(5):681-689. [PubMed: 18950458]

40. Mitchell PL, Marlton P, Grigg A, et al. A Phase II study of liposomal daunorubicin, in combination with cyclophosphamide, vincristine and prednisolone, in elderly patients with previously untreated aggressive non-Hodgkin lymphoma. Leuk Lymphoma. 2008; 49(5):924-931. [PubMed: 18464112]

41. Batist G, Ramakrishnan G, Rao CS, et al. Reduced cardiotoxicity and preserved antitumor efficacy of liposome-encapsulated doxorubicin and cyclophosphamide compared with conventional doxorubicin and cyclophosphamide in a randomized, multicenter trial of metastatic breast cancer. J Clin Oncol. 2001; 19(5):1444-1454. [PubMed: 11230490]

42. Gordon AN, Fleagle JT, Guthrie D, Parkin DE, Gore ME, Lacave AJ. Recurrent epithelial ovarian carcinoma: a randomized Phase III study of PEGylated liposomal doxorubicin versus topotecan. J Clin Oncol. 2001; 19(14):3312-3322. [PubMed: 11454878]

43. Northfelt DW, Dezube BJ, Thommes JA, et al. PEGylated-liposomal doxorubicin versus doxorubicin, bleomycin, and vincristine in the treatment of AIDS-related Kaposi's sarcoma: results of a randomized Phase III clinical trial. J Clin Oncol. 1998; 16(7):2445-2451. [PubMed: 9667262]

44. Keller AM, Mennel RG, Georgoulias VA, et al. Randomized Phase III trial of pegylated liposomal doxorubicin versus vinorelbine or mitomycin $\mathrm{C}$ plus vinblastine in women with taxane-refractory advanced breast cancer. J Clin Oncol. 2004; 22(19):3893-3901. [PubMed: 15459210]

45. Krown SE, Northfelt DW, Osoba D, Stewart JS. Use of liposomal anthracyclines in Kaposi's sarcoma. Semin Oncol. 2004; 31(6 Suppl 13):36-52. [PubMed: 15717737]

46. Harris L, Batist G, Belt R, et al. Liposome-encapsulated doxorubicin compared with conventional doxorubicin in a randomized multicenter trial as first-line therapy of metastatic breast carcinoma. Cancer. 2002; 94(1):25-36. [PubMed: 11815957]

47. Hawkins MJ, Soon-Shiong P, Desai N. Protein nanoparticles as drug carriers in clinical medicine. Adv Drug Deliv Rev. 2008; 60(8):876-885. [PubMed: 18423779]

48. Desai N, Trieu V, Yao Z, et al. Increased antitumor activity, intratumor paclitaxel concentrations, and endothelial cell transport of cremophor-free, albumin-bound paclitaxel, ABI-007, compared with cremophor-based paclitaxel. Clin Cancer Res. 2006; 12(4):1317-1324. [PubMed: 16489089]

49. Vishnu P, Roy V. Safety and efficacy of nab-paclitaxel in the treatment of patients with breast cancer. Breast Cancer (Auck1 ). 2011; 5:53-65. [PubMed: 21603258]

50. Gradishar WJ, Tjulandin S, Davidson N, et al. Phase III trial of nanoparticle albumin-bound paclitaxel compared with polyethylated castor oil-based paclitaxel in women with breast cancer. $\mathrm{J}$ Clin Oncol. 2005; 23(31):7794-7803. [PubMed: 16172456] 
51. Aapro M, Tjulandin S, Bhar P, Gradishar W. Weekly nab-paclitaxel is safe and effective in $>/=65$ years old patients with metastatic breast cancer: a post-hoc analysis. Breast. 2011; 20(5):468-474. [PubMed: 21843943]

52. Montana M, Ducros C, Verhaeghe P, Terme T, Vanelle P, Rathelot P. Albumin-bound paclitaxel: the benefit of this new formulation in the treatment of various cancers. J Chemother. 2011; 23(2): 59-66. [PubMed: 21571619]

53. Desai, N. Nanoparticle albumin bound (nab) technology: a nanotechnology platform for biologically interactive drug delivery and targeting. Presented at: The 234th ACS National Meeting; Boston, MA, USA. 19-23 August 2007;

54. Desai N, Trieu V, Damascelli B, Soon-Shiong P. SPARC Expression correlates with tumor response to albumin-bound paclitaxel in head and neck cancer patients. Transl Oncol. 2009; 2(2): 59-64. [PubMed: 19412420]

55. Koukourakis MI, Giatromanolaki A, Brekken RA, et al. Enhanced expression of SPARC/ osteonectin in the tumor-associated stroma of non-small cell lung cancer is correlated with markers of hypoxia/acidity and with poor prognosis of patients. Cancer Res. 2003; 63(17):53765380. [PubMed: 14500371]

56. Podhajcer OL, Benedetti L, Girotti MR, Prada F, Salvatierra E, Llera AS. The role of the matricellular protein SPARC in the dynamic interaction between the tumor and the host. Cancer Metastasis Rev. 2008; 27(3):523-537. [PubMed: 18459035]

57. Wiedenmann N, Valdecanas D, Hunter N, et al. 130-nm albumin-bound paclitaxel enhances tumor radiocurability and therapeutic gain. Clin Cancer Res. 2007; 13(6):1868-1874. [PubMed: 17363543]

58. Kim SH, Jeong JH, Chun KW, Park TG. Target-specific cellular uptake of PLGA nanoparticles coated with poly(L-lysine)-poly(ethylene glycol)-folate conjugate. Langmuir. 2005; 21(19):88528857. [PubMed: 16142970]

59. Zhang L, Gu FX, Chan JM, Wang AZ, Langer RS, Farokhzad OC. Nanoparticles in medicine: therapeutic applications and developments. Clin Pharmacol Ther. 2008; 83(5):761-769. [PubMed: 17957183]

60. Gu F, Zhang L, Teply BA, et al. Precise engineering of targeted nanoparticles by using selfassembled biointegrated block copolymers. Proc Natl Acad Sci USA. 2008; 105(7):2586-2591. [PubMed: 18272481]

61. Werner ME, Copp JA, Karve S, et al. Folate-targeted polymeric nanoparticle formulation of docetaxel is an effective molecularly targeted radiosensitizer with efficacy dependent on the timing of radiotherapy. ACS Nano. 2011; 5(11):8990-8998. Preclinical paper showing radiosensitizing capability with a targeted polymeric nanoparticle. [PubMed: 22011071]

62. Werner ME, Karve S, Sukumar R, et al. Folate-targeted nanoparticle delivery of chemo- and radiotherapeutics for the treatment of ovarian cancer peritoneal metastasis. Biomaterials. 2011; 32(33):8548-8554. [PubMed: 21843904]

63. Liang C, Yang Y, Ling Y, Huang Y, Li T, Li X. Improved therapeutic effect of folate-decorated PLGA-PEG nanoparticles for endometrial carcinoma. Bioorg Med Chem. 2011; 19(13):40574066. [PubMed: 21641806]

64. Esmaeili F, Ghahremani MH, Ostad SN, et al. Folate-receptor-targeted delivery of docetaxel nanoparticles prepared by PLGA-PEG-folate conjugate. J Drug Target. 2008; 16(5):415-423. [PubMed: 18569286]

65. Zhang Z, Huey Lee S, Feng SS. Folate-decorated poly(lactide-co-glycolide)-vitamin E TPGS nanoparticles for targeted drug delivery. Biomaterials. 2007; 28(10):1889-1899. [PubMed: 17197019]

66. Acharya S, Dilnawaz F, Sahoo SK. Targeted epidermal growth factor receptor nanoparticle bioconjugates for breast cancer therapy. Biomaterials. 2009; 30(29):5737-5750. [PubMed: 19631377]

67. Kocbek P, Obermajer N, Cegnar M, Kos J, Kristl J. Targeting cancer cells using PLGA nanoparticles surface modified with monoclonal antibody. J Control Release. 2007; 120(1-2):1826. [PubMed: 17509712] 
68. Koopaei MN, Dinarvand R, Amini M, et al. Docetaxel immunonanocarriers as targeted delivery systems for HER 2-positive tumor cells: preparation, characterization, and cytotoxicity studies. Int J Nanomedicine. 2011; 6:1903-1912. [PubMed: 21931485]

69. Liu Y, Li K, Liu B, Feng SS. A strategy for precision engineering of nanoparticles of biodegradable copolymers for quantitative control of targeted drug delivery. Biomaterials. 2010; 31(35):9145-9155. [PubMed: 20864169]

70. Mccarron PA, Marouf WM, Quinn DJ, et al. Antibody targeting of camptothecin-loaded PLGA nanoparticles to tumor cells. Bioconjug Chem. 2008; 19(8):1561-1569. [PubMed: 18627195]

71. Enlow EM, Luft JC, Napier ME, Desimone JM. Potent engineered PLGA nanoparticles by virtue of exceptionally high chemotherapeutic loadings. Nano Lett. 2011; 11(2):808-813. [PubMed: 21265552]

72m. Jung J, Park SJ, Chung HK, et al. Polymeric nanoparticles containing taxanes enhance chemoradiotherapeutic efficacy in non-small cell lung cancer. Int J Radiat Oncol Biol Phys. 2012; 84(1):e77-e83. Presents preclinical data on chemoradiation, which, to date, is somewhat lacking (as opposed to chemotherapy-alone publications). [PubMed: 22795728]

73. Kim SC, Kim DW, Shim YH, et al. Invivo evaluation of polymeric micellar paclitaxel formulation: toxicity and efficacy. J Control Release. 2001; 72(1-3):191-202. [PubMed: 11389998]

74. Kim DW, Kim SY, Kim HK, et al. Multicenter Phase II trial of Genexol-PM, a novel cremophorfree, polymeric micelle formulation of paclitaxel, with cisplatin in patients with advanced nonsmall-cell lung cancer. Ann Oncol. 2007; 18(12):2009-2014. [PubMed: 17785767]

75. Kim TY, Kim DW, Chung JY, et al. PhaseI and pharmacokinetic study of Genexol-PM, a cremophor-free, polymeric micelle-formulated paclitaxel, in patients with advanced malignancies. Clin Cancer Res. 2004; 10(11):3708-3716. [PubMed: 15173077]

76. Lee JL, Ahn JH, Park SH, et al. Phase II study of a cremophor-free, polymeric micelle formulation of paclitaxel for patients with advanced urothelial cancer previously treated with gemcitabine and platinum. Invest New Drugs. 2011; 30(5):1984-1990. [PubMed: 22012004]

77. Lee KS, Chung HC, Im SA, et al. Multicenter Phase II trial of Genexol-PM, a Cremophor-free, polymeric micelle formulation of paclitaxel, in patients with metastatic breast cancer. Breast Cancer Res Treat. 2008; 108(2):241-250. [PubMed: 17476588]

78. Shea JE, Nam KH, Rapoport N, Scaife CL. Genexol inhibits primary tumour growth and metastases in gemcitabine-resistant pancreatic ductal adenocarcinoma. HPB (Oxford). 2011; 13(3):153-157. [PubMed: 21309930]

79m. Hrkach J, Von Hoff D, Mukkaram Ali M, et al. Preclinical development and clinical translation of a PSMA-targeted docetaxel nanoparticle with a differentiated pharmacological profile. Sci Transl Med. 2012; 4(128):128ra139. Publication on BIND-014, a targeted nanoparticle now entering clinical trials.

80. Jung KH, Kim KP, Yoon DH, et al. A Phase I trial to determine the maximum tolerated dose and evaluate the safety and pharmacokinetics (PK) of docetaxel-PNP, polymeric nanoparticle formulation of docetaxel, in subjects with advanced solid malignancies. J Clin Oncol. 2012; 30(Suppl):abstr e13104.

81. Baker JR Jr. Dendrimer-based nanoparticles for cancer therapy. Hematology Am Soc Hematol Educ Program. 2009; 2009:708-719. [PubMed: 20008257]

82. Minelli C, Lowe SB, Stevens MM. Engineering nanocomposite materials for cancer therapy. Small. 2010; 6(21):2336-2357. [PubMed: 20878632]

83. Le Duc G, Miladi I, Alric C, et al. Toward an image-guided microbeam radiation therapy using gadolinium-based nanoparticles. ACS Nano. 2011; 5(12):9566-9574. [PubMed: 22040385]

84. Hofheinz RD, Gnad-Vogt SU, Beyer U, Hochhaus A. Liposomal encapsulated anticancer drugs. Anticancer Drugs. 2005; 16(7):691-707. [PubMed: 16027517]

85. Koukourakis MI, Koukouraki S, Giatromanolaki A, et al. Liposomal doxorubicin and conventionally fractionated radiotherapy in the treatment of locally advanced non-small-cell lung cancer and head and neck cancer. J Clin Oncol. 1999; 17(11):3512-3521. Example of nanomedicine-based chemoradiation. This was a small trial, and published over a decade ago, but shows feasbility of this combination. [PubMed: 10550149] 
86. Koukourakis MI, Romanidis K, Froudarakis M, et al. Concurrent administration of docetaxel and stealth liposomal doxorubicin with radiotherapy in non-small cell lung cancer: excellent tolerance using subcutaneous amifostine for cytoprotection. Br J Cancer. 2002; 87(4):385-392. [PubMed: 12177774]

87. Varveris H, Kachris S, Mazonakis M, et al. Pegulated liposomal doxorubicin and cisplatin given concurrently with conventional radiotherapy: a Phase I dose-escalation trial for patients with squamous cell carcinoma of head and neck and lung. Oncol Rep. 2004; 12(2):473-481. [PubMed: $15254718]$

88. Koukourakis MI, Patlakas G, Froudarakis ME, et al. Hypofractionated accelerated radiochemotherapy with cytoprotection (Chemo-HypoARC) for inoperable non-small cell lung carcinoma. Anticancer Res. 2007; 27(5B):3625-3631. [PubMed: 17972527]

89. Tsoutsou PG, Froudarakis ME, Bouros D, Koukourakis MI. Hypofractionated/accelerated radiotherapy with cytoprotection (HypoARC) combined with vinorelbine and liposomal doxorubicin for locally advanced non-small cell lung cancer (NSCLC). Anticancer Res. 2008; 28(2B):1349-1354. [PubMed: 18505077]

90. Varveris H, Kachris S, Mazonakis M, et al. Phase I/II trial of external irradiation plus mediumdose brachytherapy given concurrently to liposomal doxorubicin and cisplatin for advanced uterine cervix carcinoma. Strahlenther Onkol. 2006; 182(3):125-134. [PubMed: 16520906]

91. Koukourakis MI, Manavis J, Simopoulos C, Liberis V, Giatromanolaki A, Sivridis E. Hypofractionated accelerated radiotherapy with cytoprotection combined with trastuzumab, liposomal doxorubicine, and docetaxel in c-erbB-2-positive breast cancer. Am J Clin Oncol. 2005; 28(5):495-500. [PubMed: 16199990]

92. Nardone L, Valentini V, Marino L, et al. A feasibility study of neo-adjuvant low-dose fractionated radiotherapy with two different concurrent anthracycline-docetaxel schedules in stage IIA/B-IIIA breast cancer. Tumori. 2012; 98(1):79-85. [PubMed: 22495705]

93. Koukourakis MI, Tsolos C, Touloupidis S. Radical hypofractionated accelerated radiotherapy with cytoprotection for invasive bladder cancer. Urology. 2007; 69(2):245-250. [PubMed: 17320657]

94. Koukourakis MI, Giatromanolaki A, Pitiakoudis M, et al. Concurrent liposomal cisplatin (Lipoplatin), 5-fluorouracil and radiotherapy for the treatment of locally advanced gastric cancer: a Phase I/II study. Int J Radiat Oncol Biol Phys. 2010; 78(1):150-155. [PubMed: 20138443]

95. Rosenthal DI, Yom SS, Liu L, et al. A Phase I study of SPI-077 (Stealth liposomal cisplatin) concurrent with radiation therapy for locally advanced head and neck cancer. Invest New Drugs. 2002; 20(3):343-349. [PubMed: 12201498]

96. Miele E, Spinelli GP, Tomao F, Tomao S. Albumin-bound formulation of paclitaxel (Abraxane ABI-007) in the treatment of breast cancer. Int J Nanomedicine. 2009; 4:99-105. [PubMed: 19516888]

97. Karasawa K, Shinoda H, Katsui K, et al. Radiotherapy with concurrent docetaxel and carboplatin for head and neck cancer. Anticancer Res. 2002; 22(6B):3785-3788. [PubMed: 12552993]

98. Nabell L, Spencer S. Docetaxel with concurrent radiotherapy in head and neck cancer. Semin Oncol. 2003; 30(6 Suppl 18):89-93. [PubMed: 14727247]

99. Saba NF, Wang X, Muller S, et al. Examining expression of folate receptor in squamous cell carcinoma of the head and neck as a target for a novel nanotherapeutic drug. Head Neck. 2009; 31(4):475-481. [PubMed: 19072997]

100. Zhao P, Astruc D. Docetaxel nanotechnology in anticancer therapy. ChemMedChem. 2012; 7(6): 952-972. [PubMed: 22517723]

101. Davis ME, Zuckerman JE, Choi CH, et al. Evidence of RNAi in humans from systemically administered siRNA via targeted nanoparticles. Nature. 2010; 464(7291):1067-1070. [PubMed: 20305636]

102. Zou J, Qiao X, Ye H, et al. Inhibition of ataxia-telangiectasia mutated by antisense oligonucleotide nanoparticles induces radiosensitization of head and neck squamous-cell carcinoma in mice. Cancer Biother Radiopharm. 2009; 24(3):339-346. [PubMed: 19435407]

103. Tarhini AA, Belani CP, Luketich JD, et al. A Phase I study of concurrent chemotherapy (paclitaxel and carboplatin) and thoracic radiotherapy with swallowed manganese superoxide 
dismutase plasmid liposome protection in patients with locally advanced stage III non-small-cell lung cancer. Hum Gene Ther. 2011; 22(3):336-342. [PubMed: 20873987]

104. Herold DM, Das IJ, Stobbe CC, Iyer RV, Chapman JD. Gold microspheres: a selective technique for producing biologically effective dose enhancement. Int J Radiat Biol. 2000; 76(10):13571364. [PubMed: 11057744]

105. Cho SH. Estimation of tumour dose enhancement due to gold nanoparticles during typical radiation treatments: a preliminary Monte Carlo study. Phys Med Biol. 2005; 50(15):N163N173. [PubMed: 16030374]

106. Hainfeld JF, Slatkin DN, Smilowitz HM. The use of gold nanoparticles to enhance radiotherapy in mice. Phys Med Biol. 2004; 49(18):N309-N315. [PubMed: 15509078]

107. Field JA, Luna-Velasco A, Boitano SA, et al. Cytotoxicity and physicochemical properties of hafnium oxide nanoparticles. Chemosphere. 2011; 84(10):1401-1407. [PubMed: 21605889]

108-. Karve S, Werner ME, Sukumar R, et al. Revival of the abandoned therapeutic wortmannin by nanoparticle drug delivery. Proc Natl Acad Sci USA. 2012; 109(21):8230-8235. Wortmannin is a previously abandoned therapy due to systemic toxicity. This paper shows that it may be revived when delivered on a nanoparticle platform. [PubMed: 22547809]

\section{Websites}

201. Search for 'Abraxane', excluding 'Unknown status' on www.clinicaltrials.gov. http:// clinicaltrials.gov/ct2/results?term=abraxane

202. ClinicalTrials database: NCT01300533. http://clinicaltrials.gov/show/NCT01300533

203. ClinicalTrials.gov. www.clinicaltrials.gov

204. Search for 'Abraxane' and 'Concurrent' and 'Radiation' on www.clinicaltrials.gov. http:// clinicaltrials.gov/ct $2 /$ results?term =abraxane+AND+concurrent+AND+radiation $\&$ Search=Search

205. ClinicalTrials database: NCT00689065. http://clinicaltrials.gov/show/NCT00689065

206. ClinicalTrials database: NCT01433068. http://clinicaltrials.gov/show/NCT01433068 


\section{Executive summary}

\section{Nanoparticle advantages in chemoradiation}

- Nanoparticles exhibit properties that may be of particular benefit when treating cancer patients with combined chemotherapy and radiation therapy. This includes the enhanced permeability and retention effect.

\section{Nanoparticle therapeutics under preclinical \& clinical evaluation}

- There are five major categories of nanoparticles: liposomes, albumin-bound nanoparticles, polymeric nanoparticles, dendrimers, and metal nanoparticles.

- There are a handful already approved for clinical use in cancer (Table 1), with many more in preclinical and clinical development across medicine.

\section{Nanoparticle therapeutics used in chemoradiation}

- While clinical approval exists for only a few nanoparticle chemotherapeutics, even fewer have clearly defined roles in chemoradiation. There are a number of small clinical trials that have been pursued, but widespread use of this combined approach is yet to be realized clinically.

- Newer combinations, such as BIND-014, are combining nanomedicine with targeting and may create another opportunity to pursue treatment with nanoparticle-based chemoradiation

- Nanomedicine may revitalize previously abandoned therapeutics, such as Wortmannin, by developing safe delivery mechanisms of otherwise systemically toxic therapies.

\section{Future perspective}

- Applications of nanomedicine in chemoradiation hold great potential, but there remains a wide chiasm between translating results of drug development into clinical application.

- There is a need for more clinical trials of nanomedicine applied specifically in the chemoradiation setting.

- Greater cross-discipline collaboration is needed to accelerate the movement from preclinical promise to clinical delivery in order to provide the most benefit to patients. 
Table 1

Clinically approved nanoparticle therapeutics.

\begin{tabular}{|lll|}
\hline Category & Drug names & Indications \\
\hline Liposome & DaunoXome $^{\circledR}($ liposomal daunorubicin $)$ & $\begin{array}{l}\text { AIDS-related Kaposi's sarcoma, acute myeloid } \\
\text { leukemia and non-Hodgkin lymphoma }\end{array}$ \\
\hline Liposome & Doxil $^{\circledR} /$ Caelyx $^{\circledR}($ PEGylated liposomal doxorubicin $)$ & $\begin{array}{l}\text { AIDS-related Kaposi's sarcoma, multiple myeloma } \\
\text { and ovarian and breast cancer }\end{array}$ \\
\hline Liposome & Myocet $^{\circledR}($ non-PEGylated liposomal doxorubicin $)$ & Breast cancer \\
\hline Albumin-bound nanoparticles & Abraxane $^{\circledR}($ albumin-bound paclitaxel $)$ & Metastatic breast cancer \\
\hline
\end{tabular}

